\title{
A circular toxicity approach to isoprostanes: From markers of oxidative stress, to epidemiological warning systems and agents of aquatic toxicity ${ }^{\underline{2}}$
}

\author{
Ricardo Teles Pais a , Ana C.A. Sousa a, b, c, d, * , M. Ramiro Pastorinho a, d, e \\ ${ }^{a}$ CICS-UBI - Health Sciences Research Centre, University of Beira Interior, Av. Infante D. Henrique, 6200-506, Covilhã, Portugal \\ ${ }^{\mathrm{b}}$ CNRS LAbEx DRIIHM, CNRS - INEE - ECCOREV (Unité FR3098), OHMi Estarreja-OHM Bassin Minier de Provence, Europôle méditerranéen de L'Arbois, Bât \\ du CEREGE - BP 80, 13545, Aix en Provence Cedex 4, France \\ ${ }^{\mathrm{c}}$ CICECO - Aveiro Institute of Materials, Department of Chemistry, University of Aveiro, 3810-193, Aveiro, Portugal \\ ${ }^{\mathrm{d}}$ NuESA - Health and Environment Study Unit, Faculty of Health Sciences, University of Beira Interior, 6200-506, Covilhã, Portugal \\ ${ }^{\mathrm{e}}$ Faculty of Health Sciences, University of Beira Interior, 6200-506, Covilhã, Portugal
}

\section{A R T I C L E I N F O}

\section{Article history:}

Received 11 March 2018

Received in revised form

3 September 2018

Accepted 5 September 2018

Available online 6 September 2018

\section{Keywords:}

Lipid peroxidation

Oxidative stress

Sewage epidemiology

Ecotoxicity

\begin{abstract}
A B S T R A C T
Isoprostanes (IsoPs) are a class of oxidation products naturally formed in vivo that are indicative of endogenous oxidative stress. In individuals with chronic and oxidative stress related diseases, IsoPs are increased to pathological levels. Since they are excreted through urine into sewage systems, IsoPs can be detected in wastewater treatment plants' (WWTPs) effluents and thus can be used to evaluate the health status of a given population. The underlying principle is that higher isoprostanes WWTPs' levels correspond to populations undergoing higher levels of oxidative stress, and thus disease. However, IsoPs are not eliminated by WWTPs and will end up being released into the aquatic environment, where they will be available for uptake by aquatic species. Being bioactive molecules, it has been suggested that IsoPs in the environment may elicit oxidative stress in aquatic organisms. In this context, we have critically reviewed the available data on IsoPs as products and effectors of toxicity, and propose the new concept of "circular toxicity". In general, IsoPs excreted by humans as a consequence of oxidative stress are released into the aquatic environment where they may interact with aquatic organisms and induce the production of more IsoPs. These stress markers, in turn, will also be excreted, increasing the already high levels of stressors in the aquatic environment and thus create an escalating cycle of oxidative stress.
\end{abstract}

() 2018 Elsevier Ltd. All rights reserved.

\section{Introduction}

In homeostatic conditions, there is an equilibrium in the redox status. However, certain stressors can elicit a response that disrupts this homeostatic state, inducing an imbalance between oxidants and antioxidants, in favour of the oxidants. This leads to the prevalence of supraphysiological oxidative stress, disrupting redox signalling and/or damaging biomolecules, which may ultimately lead to the onset of disease (Pisoschi and Pop, 2015). In fact, oxidative stress plays a major role in several chronic and non-

\footnotetext{
This paper has been recommended for acceptance by Dr. Harmon Sarah Michele.

* Corresponding author. CICS-UBI - Health Sciences Research Centre, University of Beira Interior, Av. Infante D. Henrique, 6200-506, Covilhã, Portugal.

E-mail address: anasousa@fcsaude.ubi.pt (A.C.A. Sousa).
}

communicable diseases including for example cancer, diabetes, autoimmune disorders, neurodegenerative and cardiovascular diseases (Andersen, 2004; Pham-Huy et al., 2008). However, it affects not only humans but all living organisms, and the effects of oxidative stress in wildlife and its role on the shaping of lifehistories is a topic of growing concern in the scientific community (Costantini et al., 2010; Dowling and Simmons, 2009; Metcalfe and Alonso-Alvarez, 2010; Salin et al., 2017).

Oxidants (or pro-oxidants) correspond to any endobiotic or xenobiotic capable of inducing oxidative stress, either by generating free radicals or affecting the antioxidant response efficacy (Rahal et al., 2014). Generally, oxidative damage occurs due to free radicals, which may originate from several reactive species such as reactive oxygen species, and, to a lesser extent, reactive species of nitrogen, carbon, copper, halogens, iron and sulphur. Free radicals are chemical species capable of existing independently. They have an unpaired valence electron in their external orbit becoming 
highly unstable, and consequently very reactive, hence short lived (Lushchak, 2014; Pisoschi and Pop, 2015). They are involved, for example, in lipid peroxidation and consequent formation of different molecules in which isoprostanes (IsoPs) are included.

\section{Isoprostanes synthesis and classification}

IsoPs are a class of prostaglandin-like compounds that are generally produced non-enzymatically by the peroxidation of polyunsaturated fatty acids (PUFAs) (Milne et al., 2015). The main differences between IsoPs and prostaglandins (PGs) are associated with their synthesis and stoichiometry (Fig. 1a). PGs production is associated with tissue inflammation being synthesized when arachidonic acid is released from phospholipids (by the action of phospholipase $\mathrm{A}_{2}$ ) and afterwards metabolized by cyclooxygenases (COX) (Ricciotti and FitzGerald, 2011; Yen et al., 2015). IsoPs are a result of the peroxidation induced by free radicals in PUFAs (lipid peroxidation). In this context, lipid peroxidation consists in the interaction of free radicals with PUFAs that, upon oxidation, will consequently propagate a series of lipidic oxidations until this chain reaction is interrupted (Ayala et al., 2014; Kalyanaraman, 2013; Milne et al., 2011). This process is summarized in Fig. 1b. Therefore, IsoPs generation is traditionally considered to be enzyme independent (Milne et al., 2011). Recently, some authors have been questioning the established paradigm that IsoPs formation is independent of enzymatic action. van't Erve et al. (2016) added important evidence that IsoPs are not solely products of oxidation induced by free radicals (independent of enzymes) but can also be obtained through enzymatic oxidation via COX, just like PGs. In practical terms, these authors highlighted that, in order to better characterize the real contribution of oxidative stress, one should examine the ratio of a specific IsoP to its respective PG generated by COX: the enzymatic pathway is responsible for a higher proportion of the latter over the former, whereas the proportion is similar when oxidative stress is the mechanism underlying the formation of these compounds (van't Erve et al., 2016).

The second major difference between PGs and IsoPs is their stoichiometry: whereas the two PG side chains have a trans conformation relative to the cyclopentane ring (thermodynamically favourable), the two side chains of IsoPs have a cis conformation (kinetically favourable) (Daughton, 2012). The categorization of IsoPs is performed based on the functional groups that are present along their prostane ring. They are named based on the structure of the functional groups present in its cyclopentane ring, being $\mathrm{F}_{2^{-}}, \mathrm{D}_{2}$-and $\mathrm{E}_{2}$-IsoPs the main classes to be considered when arachidonic acid is the oxidized PUFA (Jahn et al., 2008; Milne et al., 2011). Of these three isomers, $F_{2}$-IsoPs are the most stable when compared to $\mathrm{D}_{2}$-and $\mathrm{E}_{2}$-IsoPs because these two are dehydrated to $\mathrm{J}_{2}$-and $\mathrm{A}_{2}$-IsoPs, respectively (Milne et al., 2011). $\mathrm{F}_{2}$-IsoPs have several isomers (up to 64 are possible), depending on where the oxidation of arachidonic acid occurs (Gaw and Glover, 2016; Yen et al., 2015). This number of isomers is possible because, when arachidonic acid is subject to lipid peroxidation by free radicals, it produces four regioisomers and each of these will, in turn, give rise to eight additional isomers together with their respective diastereomers (Daughton, 2012). The four regioisomers have a classification to discriminate them from each other, taking into account the carbon where the hydroxyl group is and starting counting from the carbon of the carboxyl group. By doing this, hydroxyl groups can be bound to different carbons which occupy positions $5,8,12$ or 15 , and, therefore, $\mathrm{F}_{2}$-IsoPs will be present in the form of $5-\mathrm{F}_{2}$-IsoPs, $8-\mathrm{F}_{2}$-IsoPs, $12-\mathrm{F}_{2}$-IsoPs and $15-\mathrm{F}_{2}$-IsoPs, respectively. It is important to note that the regioisomers of the 5- and 15-series are formed at significantly higher amounts than the regioisomers of the 8- and 12 -series because the latter are still susceptible to oxidation. Thus, since regioisomers of series 5 - and 15 -series are not oxidized, they correspond to the final products of the overall oxidation reaction (Milne et al., 2011). As a consequence, these IsoPs are considered as a marker of the occurrence of lipid peroxidation and, consequently, an indicator of oxidative stress.

\section{Isoprostanes as markers of oxidative stress}

Oxidative stress is, as previously mentioned, associated with several chronic non-communicable diseases and thus indicators of oxidative stress can be used as clinical biomarkers. On this basis, $\mathrm{F}_{2}-$ IsoPs, $15-\mathrm{F}_{2}$-IsoPs and its metabolites, and also $5-\mathrm{F}_{2}$-IsoPs have been quantified in patients aiming to relate their levels with pathologies known to be associated with lipid peroxidation and, thus, with oxidative stress (Galano et al., 2017).

Generally, $15-\mathrm{F}_{2}$-IsoPs (also known as 8-iso- $\mathrm{PGF}_{2 \alpha}$ ), are the most abundant $\mathrm{F}_{2}$-IsoPs. They can be detected in plasma (free IsoPs) and urine (free and glucuronide-conjugated IsoPs) (Gaw and Glover, 2016; Milne et al., 2015). Several authors have quantified $F_{2}$-IsoPs levels in both matrices. Morrow et al. (1990) established for the first time the normal levels of $\mathrm{F}_{2}$-IsoPs both for plasma $(0.005-0.04 \mathrm{ng}$ $\left.\mathrm{mL}^{-1}\right)$ and in urine $\left(0.5-4 \mathrm{ng} \mathrm{mg}^{-1}\right.$ creatinine). Later, Liu et al. (1999) reported that the normal levels were $0.035 \pm 0.006 \mathrm{ng}$ $\mathrm{mL}^{-1}$ for human plasma and $1.6 \pm 0.6 \mathrm{ng} \mathrm{mg}^{-1}$ creatinine for urine. More recently, van 't Erve et al. (2017), reported urinary levels of $1.2 \pm 0.6 \mathrm{ng} \mathrm{mL}^{-1}$ (or $1.3 \pm 0.8 \mathrm{ng} \mathrm{mg}^{-1}$ creatinine) in control individuals and plasma levels of $0.0451 \pm 0.0184 \mathrm{ng} \mathrm{mL} \mathrm{m}^{-1}$. Because urinary levels of free $15-\mathrm{F}_{2}$-IsoPs are much higher than those in plasma, urine is currently the preferred matrix to quantify $\mathrm{F}_{2}$-IsoPs,

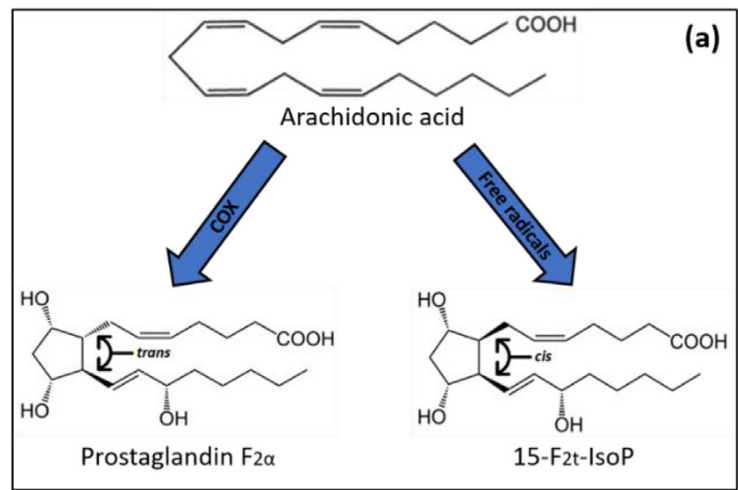

\begin{tabular}{|l} 
Initiation: $\quad \mathrm{LH}+\mathrm{R} \cdot \rightarrow \mathrm{L} \cdot+\mathrm{RH}$ \\
Propagation: $\quad \mathrm{L} \cdot+\mathrm{O}_{2} \rightarrow \mathrm{LOO} \cdot$ \\
$\mathrm{LOO} \cdot+\mathrm{LH} \rightarrow \mathrm{LOOH}+\mathrm{L} \cdot$ \\
TeO $+\mathrm{A} \rightarrow \mathrm{LOOH}+\mathrm{A}$. \\
$\mathrm{A} \cdot+\mathrm{LOO} \cdot \rightarrow \mathrm{A}_{\mathrm{OX}}+\mathrm{LOOH}$
\end{tabular}

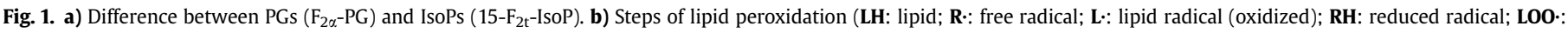
lipid peroxyl radical; LOOH: lipid hydroperoxide; A: antioxidant; A•: antioxidant radical; $\mathbf{A}_{\mathbf{o x}}$ : oxidized antioxidant (stable)). Adapted from (Kalyanaraman, 2013). 
with the additional advantage of being non-invasive, which facilitates its collection. In addition to plasma and urine, other matrices such as amniotic fluid, central nervous systems samples (anterior cingulate cortex, occipital cortex, cerebrospinal fluid, other brain tissues), atherosclerotic plaques, carotid plaques, cord serum, exhaled breath condensate, proximal gastric mucosa, saliva, serum and sputum, may be used, as comprehensibly described by Galano et al. (2017) and illustrated in Fig. 2; however, their use is still limited.

Traditionally, higher IsoPs levels were associated, for example, with neurodegenerative diseases, cancer and obesity as depicted in Fig. 2. However, upon the paradigm change proposed by van't Erve et al. (2016) (see section 2) new evidences arose and the list of diseases associated with higher IsoPs levels was revised and updated (van 't Erve et al., 2017). These authors performed a metaanalysis in order to understand the role of oxidative stress markers (free and total 8-iso- $\mathrm{PGF}_{2 \alpha}$ ) across human disease and compiled the available data for free 8-iso-PGF $2 \alpha$ and total 8-iso-PGF $2 \alpha$. The difference between these is that total 8-iso- $\mathrm{PGF}_{2 \alpha}$ includes free 8-iso$\mathrm{PGF}_{2 \alpha}$ and 8 -iso- $\mathrm{PGF}_{2 \alpha}$ that is esterified to LDL phospholipids. Overall, the authors consider that the total 8 -iso-PGF $2 \alpha$ is a better indicator of oxidative stress because, if only free 8 -iso-PGF $2 \alpha$ is assessed, it can include the enzymatically generated 8-iso-PGF $2 \alpha$, and, therefore, compromise the correct interpretation of 8-iso$\mathrm{PGF}_{2 \alpha}$ as a biomarker of oxidative stress. Thus, pathologies that have total 8-iso- $\mathrm{PGF}_{2 \alpha}$ levels higher than the free 8-iso-PGF $2 \alpha$ levels will, most likely, be non-enzymatically generated, as a consequence of oxidative stress. However, the number of publications with total 8 -iso-PGF $2 \alpha$ levels $(n=33)$ is much lower than the number of publications reporting free 8 -iso- $\mathrm{PGF}_{2 \alpha}(\mathrm{n}=209)$ (van 't Erve et al., 2017), most probably due to the difficulties associated with the quantification of total 8-iso- $\mathrm{PGF}_{2 \alpha}$ levels. Based on the results obtained from the meta-analysis, van't Erve and co-workers established a new and more robust ranking of human pathologies in which lipid peroxidation has higher interference. Diseases of the respiratory tract such as cystic fibrosis, pulmonary arterial hypertension and urogenital diseases such as chronic renal insufficiency were recognized as those for which the extension of oxidative damage is higher. On the other hand, Alzheimer's disease, obesity and cancer, that were previously associated with significant oxidative stress, presented lower association with increased levels of 8-iso-PGF $2 \alpha$ (Milne, 2017).

\section{Isoprostanes as biomarkers in wastewater-based epidemiology}

In modern society, urine is discharged into the wastewater system and thus IsoPs will follow this path. Given that the excreted IsoPs are a measure of oxidative stress, it is plausible to assume that wastewater can be used to provide a global picture of the overall oxidative stress of populations. This concept known as wastewaterbased epidemiology (WBE) or "sewage epidemiology" is based on the principle that wastewater can be regarded as a large composite urine sample from a given population (Santos et al., 2015). WBE was initially proposed to evaluate the use of substances of abuse, such as illicit drugs (Zuccato et al., 2005), and it was later extended to other such substances of abuse (alcohol and tobacco), environmental contaminants and pharmaceuticals. The usefulness of WBE is by now well-established, leading to its recommendation by the European Monitoring Centre for Drugs and Drug Addiction (EMCDDA, 2016). Besides being used to estimate the use of illicit drugs in a given population, WBE has also been used to access

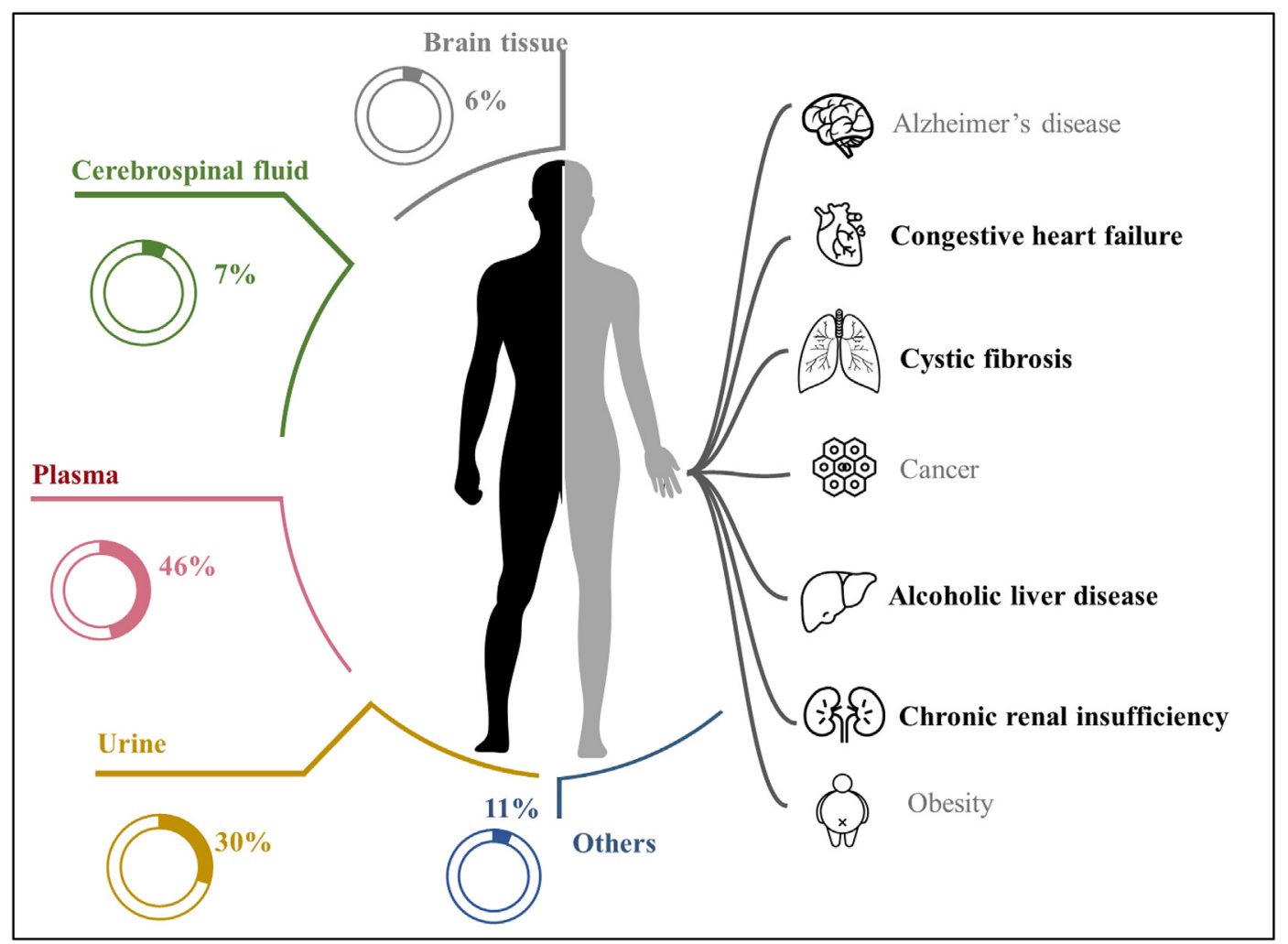

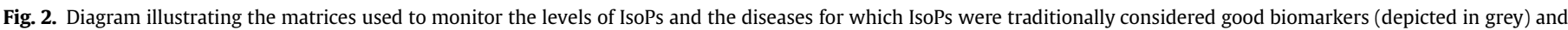

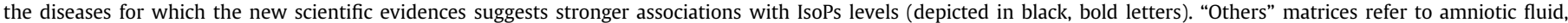

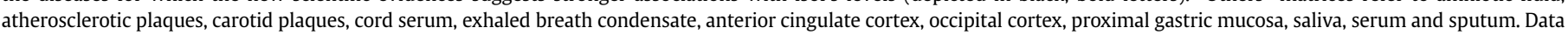
extracted from Galano et al. (2017), Milne (2017) and van 't Erve et al. (2017). 
population exposure to environmental contaminants (Been et al., 2017; Gonzalez-Marino et al., 2017; Rousis et al., 2017) and as a valuable tool to access the general consumption of pharmaceuticals and thus to indirectly assess the health status of a population (Eggimann et al., 2017; Gracia-Lor et al., 2017; Rico et al., 2017; Thomas et al., 2017). The same principle can be applied to evaluate the presence of human endogenous biomarkers of disease (Daughton, 2012, 2018; Gracia-Lor et al., 2017; Ryu et al., 2016). By measuring endogenous biomarkers that provide an indication of the disease instead of measuring the pharmaceuticals used to treat those diseases it is possible to use WBE as a warning system. Furthermore, the data obtained from endogenous biomarkers can also be used to reveal health disparities between different populations as suggested by Gracia-Lor et al. (2017). Therefore, IsoPs, particularly $15-\mathrm{F}_{2}$-IsoPs can also be used as WBE biomarkers: they are time-integrative regarding systemic oxidative stress, are excreted in urine and are stable as mentioned by Daughton (2012). However, measurement of IsoPs levels in sewage epidemiology has not received much attention judging by the small amount of studies published $(n=4)$. Fig. 3 summarizes the distribution of 8 -iso-PGF $2 \alpha$ levels reported in Europe and North America, the only locations studied so far.

Santos et al. (2015) performed the first study that addressed IsoPs levels in wastewater in Detroit, Michigan (USA). The authors collected wastewater samples once from three different points in Detroit, between May and June of 2014 and detected 8-IsoP (a synonym to $15-\mathrm{F}_{2}$-IsoPs) at levels between 6 and $20 \mathrm{ng} \mathrm{L}^{-1}$. Taking into account the flow rate and population, they concluded that the levels of IsoPs were community-dependent and remained constant over a period of two months. The same team (Santos et al., 2016) also quantified the levels of IsoPs in wastewater from Michigan over a period of one year between April of 2014 and May of 2015 using three different collection points, and reported IsoPs concentrations up to $20 \mathrm{ng} \mathrm{L}^{-1}$.

The subsequent studies were all performed in Europe with levels of IsoPs being described for 8 countries in a total of 11 cities. Ryu et al. (2015) reported the first concentrations while validating a new method to quantify IsoPs in wastewater by liquid chromatography-high resolution mass spectrometry coupled to an immunoaffinity clean-up. Integrative wastewater samples were collected in Oslo (Norway) in March of 2015 for eight consecutive days and the quantified 8 -iso- PGF $_{2 \alpha}$ levels varied between 18.9 and $23.3 \mathrm{ng} \mathrm{L}^{-1}$. Taking into account that urinary IsoPs might be in the form of glucuronide conjugates, the authors treated their wastewater sample with $\beta$-glucuronidase, in order to determine the total (free + conjugated) concentration of 8 -iso-PGF $2 \alpha$. Their results showed that, when treated with this enzyme, 8 -iso-PGF 20 concentration increased, confirming that IsoPs as glucuronide conjugates can go undetected. Such results highlighted the complexity in the evaluation of the levels of this biomarker in real samples and strengthen the conclusions by van't Erve et al. (2016) that total 8 -iso- $\mathrm{PGF}_{2 \alpha}$ is a better indicator of oxidative stress (section 3).

The same team -Ryu and co-workers (Ryu et al., 2016) - also performed the most comprehensive study up to date. They studied the levels of IsoPs in wastewater from different European cities. The work aimed to understand if there was a correlation between the levels of IsoPs and biomarkers of alcohol (ethyl sulphate) and tobacco (trans-3'-hydroxycotinine) consumption, in order to further validate the use of IsoPs as a biomarker of population health in wastewater. Previous studies demonstrated that tobacco and alcohol consumption were responsible for an increase in the relative $F_{2}$-IsoPs levels in relation to controls (Daughton, 2012). Sampling was performed over 4 or 7 consecutive days between 2014 and 2015. The results depicted concentrations of 8 -iso- $\mathrm{PGF}_{2 \alpha}$ between 8.7 and $11.9 \mathrm{ng} \mathrm{L}^{-1}$ in Brussels (Belgium); 15.6-17.8 $\mathrm{ng} \mathrm{L}^{-1}$ in Copenhagen (Denmark); 14.6-16.7 $\mathrm{ng} \mathrm{L}^{-1}$ in Utrecht (The Netherlands); $11.2-13.8 \mathrm{ng} \mathrm{L}^{-1}$ in Castellon (Spain); 14.6-18.0 $\mathrm{ng} \mathrm{L}^{-1}$ in Zurich (Switzerland); 10.1-13.6 $\mathrm{ng} \mathrm{L}^{-1}$ in Bristol (UK); 9.8-11.2 $\mathrm{ng} \mathrm{L}^{-1}$ in Milan (Italy); 9.4-11.9 $\mathrm{ng} \mathrm{L}^{-1}$ in Hamar (Norway); $13.9-17.7 \mathrm{ng} \mathrm{L}^{-1}$ in Stavanger (Norway); 15.0-17.4 $\mathrm{ng} \mathrm{L}^{-1}$ in Tromsø (Norway) and 13.9-17.0 ng $\mathrm{L}^{-1}$ in Oslo (Norway). The obtained results, demonstrated that there was a strong correlation between oxidative stress and tobacco consumption from composite wastewater samples of eleven different cities. Thus, the authors suggested that the analysis of $F_{2}$-IsoPs in untreated sewage is an advantageous tool in both diagnosis and prognosis for clinical research (Ryu et al., 2016).

\section{Isoprostanes in the context of circular toxicity}

The same characteristics that makes IsoPs a suitable WBE biomarker, i.e., their stability in wastewater (Ryu et al., 2015), ubiquity (Ryu et al., 2016) and biological activity (Daughton, 2012), may also be regarded as of potential concern towards the aquatic environment.

IsoPs are products but also effectors of oxidative stress, and therefore as proposed by Gaw and Glover (2016), there is a possibility that exposure to IsoPs from wastewaters, triggers a so-called "contagious toxicity" effect that may be responsible for the propagation of oxidative stress through the aquatic environment. As such, IsoPs were already considered as potential emerging contaminants (Gaw and Glover, 2016). The possible role of IsoPs as an

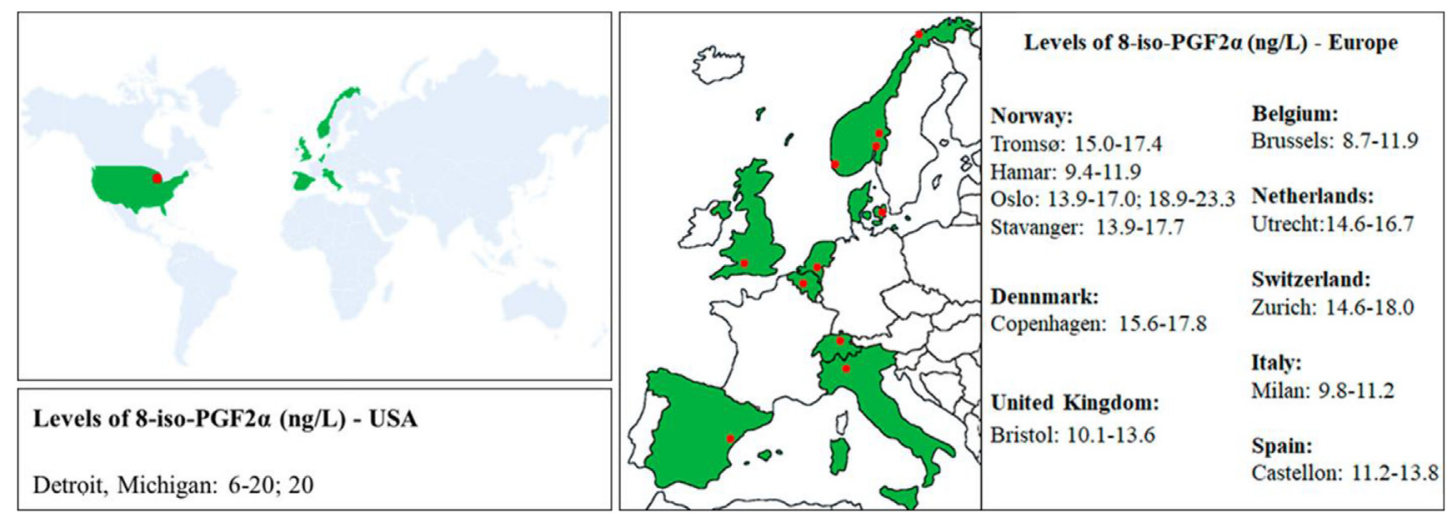

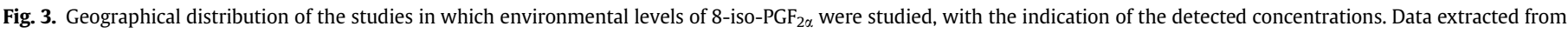
Ryu et al. (2016), Santos et al. (2015, 2016). 
emerging class of contaminants gains strength if we consider that aquatic organisms possess phylogenetically conserved prostanoid receptors as described by Mizutani et al. (2010). Given that IsoPs are basically PG-like biomolecules, they will, most probably, interact with these receptors (Heckmann et al., 2008; Lang et al., 2010). Furthermore, IsoPs were already found in fishes suggesting that they are produced by these aquatic species (Chung et al., 2013; Spokas et al., 2008). Moreover, such production was associated with lipid peroxidation after exposure to toxic metals in fathead minnow (Spokas et al., 2008).

Fig. 4 summaries our hypothesis of isoprostanes circular toxicity. We postulate that when humans are exposed to environmental or endogenous stressors, oxidative stress might occur, leading to the production of oxidative stress markers, in which isoprostanes are included. These IsoPs are excreted through urine that is discharged in the sewage system and will reach WWTPs. Because most WWTPs lack the technology to completely remove IsoPs they will enter the aquatic ecosystem, increasing its background levels. In the aquatic environment, IsoPs will be available for uptake by aquatic species and as a consequence they will probably induce additional stress in these organisms that will react by producing more oxidative stress markers (i.e. IsoPs). This production of IsoPs will lead to added excretion into the environment, which in turn will promote higher uptake of IsoPs by the aquatic organisms, thus creating a circular toxicity loop.

\section{Limitations and future perspectives}

The introduction by wastewaters of IsoPs in the aquatic environment and their potential effects upon aquatic species is a matter of concern that needs to be addressed. However, establishing that IsoPs are reaching the aquatic environment and that aquatic species will interact with these chemicals does not constitute proof in itself of deleterious effects. Studies on the toxicity of IsoPs are thus necessary; however, little attention has been directed to the potential toxicity of IsoPs towards aquatic species. In fact, to this date, a search on Scopus, PubMed and Web of Science does not produce a single article that directly addresses the effects of IsoPs as an environmental contaminant in aquatic biota itself. Therefore, there is an urgent need to evaluate the possible ecotoxicological impact that IsoPs may have on the aquatic biota of effluent receiving waters as already stated by Gaw and Glover (2016). Future studies should include the evaluation of sub-lethal effects of IsoPs into species of different taxonomic groups, representative of different trophic levels.

Besides, given the increasing incidence in developing countries of non-communicable diseases that have at its base inflammation mechanisms (i.e., obesity, diabetes, cancer, and cardiovascular, chronic respiratory and neurological diseases) intimately connected with oxidative stress (Camps and García-Heredia, 2014), an increase in the excretion of IsoPs is expected. In order to fully address this problem, it will also be necessary in the future to quantify the levels of IsoPs excreted in influents and effluents of wastewater treatment plants and to develop new technologies to allow their complete removal. Additionally, more comprehensive surveys on the environmental levels of IsoPs should also be performed.

\section{Conclusions}

Oxidative stress is a conserved widespread toxic mechanism, therefore, aquatic biota exposed to IsoPs released from WWTPs may respond to this insult by triggering additional oxidative stress, and thus may amplify oxidative stress throughout the environment

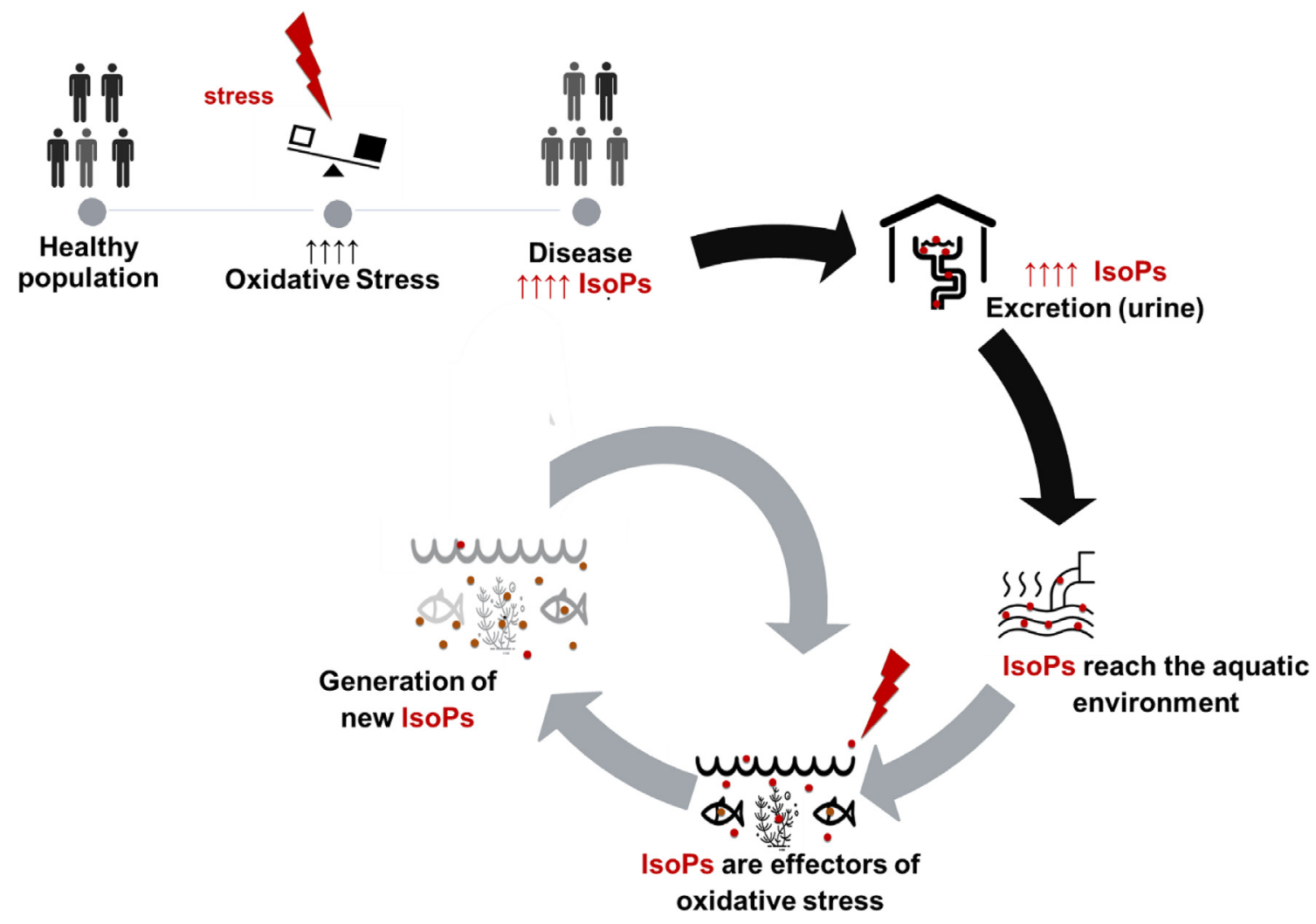

Fig. 4. Conceptual diagram of the circular toxicity hypothesis. 
as a contagious disease. As such, IsoPs possess the necessary characteristics to become a case of circular toxicity: the more IsoPs are excreted by humans the greater amount of these chemicals will be concentrated in WWTPs and afterwards released into the aquatic environment where they will putatively impact aquatic biota. These impacts will at least partially translate into further oxidative stress, leading to the consequent excretion of more IsoPs, perpetuating the cycle.

\section{Conflicts of interest}

The authors declare that they have no conflict of interest.

\section{Acknowledgments}

This work was financially supported by FEDER funds through the POCI - COMPETE 2020 - Operational Programme Competitiveness and Internationalisation in Axis I - Strengthening research, technological development and innovation (Project POCI-01-0145FEDER-007491) and Portuguese National Funds by FCT - Foundation for Science and Technology (Project UID/Multi/00709/2013 and project UID/CTM/50011/2013). Further financial support was provided by "Interdisciplinary Challenges on Neurodegeneration (ICON)" (Ref. CENTRO-01-0145-FEDER-000013). Ana C.A. Sousa also acknowledges the financial support of Labex DRIIHM (PIA), via OHMI Estarreja - OHM Bassin Minier de Provence, International Observatory Hommes-Millieux, tool of CNRS/INEE - National Center for Scientific Research/Institute of Ecology and Environment, France.

The authors would like to acknowledge the three anonymous reviewers that were determinant upon the shaping of the present version of the manuscript.

\section{References}

Andersen, J.K., 2004. Oxidative stress in neurodegeneration: cause or consequence? Nat. Med. 10 (Suppl. 1), S18-S25.

Ayala, A., Munoz, M.F., Arguelles, S., 2014. Lipid peroxidation: production, metabolism, and signaling mechanisms of malondialdehyde and 4-hydroxy-2nonenal. Oxid Med Cell Longev 2014, 360438.

Been, F., Bastiaensen, M., Lai, F.Y., van Nuijs, A.L.N., Covaci, A., 2017. Liquid chromatography-tandem mass spectrometry analysis of biomarkers of exposure to phosphorus flame retardants in wastewater to monitor communitywide exposure. Anal. Chem. 89, 10045-10053.

Camps, J., García-Heredia, A., 2014. Introduction: oxidation and inflammation, a molecular link between non-communicable diseases. In: Camps, J. (Ed.), Oxidative Stress and Inflammation in Non-communicable Diseases - Molecular Mechanisms and Perspectives in Therapeutics. Springer International Publishing, pp. $1-4$.

Chung, M.L., Lee, K.Y., Lee, C.Y., 2013. Profiling of oxidized lipid products of marine fish under acute oxidative stress. Food Chem. Toxicol. 53, 205-213.

Costantini, D., Rowe, M., Butler, M.W., McGraw, K.J., 2010. From molecules to living systems: historical and contemporary issues in oxidative stress and antioxidant ecology. Funct. Ecol. 24, 950-959.

Daughton, C.G., 2012. Using biomarkers in sewage to monitor community-wide human health: isoprostanes as conceptual prototype. Sci. Total Environ. 424 $16-38$

Daughton, C.G., 2018. Monitoring wastewater for assessing community health: Sewage Chemical-Information Mining (SCIM). Sci. Total Environ. 619-620, $748-764$.

Dowling, D.K., Simmons, L.W., 2009. Reactive oxygen species as universal constraints in life-history evolution. Proc. Biol. Sci. 276, 1737-1745.

Eggimann, S., Mutzner, L., Wani, O., Schneider, M.Y., Spuhler, D., Moy de Vitry, M., Beutler, P., Maurer, M., 2017. The potential of knowing more: a review of datadriven urban water management. Environ. Sci. Technol. 51, 2538-2553.

EMCDDA, 2016. Assessing Illicit Drugs in Wastewater: Advances in Wastewaterbased Drug Epidemiology. Insights.

Galano, J.M., Lee, Y.Y., Oger, C., Vigor, C., Vercauteren, J., Durand, T., Giera, M., Lee, J.C., 2017. Isoprostanes, neuroprostanes and phytoprostanes: an overview of 25years of research in chemistry and biology. Prog. Lipid Res. 68, 83-108.

Gaw, S., Glover, C.N., 2016. A case of contagious toxicity? Isoprostanes as potentia emerging contaminants of concern. Sci. Total Environ. 560-561, 295-298.
Gonzalez-Marino, I., Rodil, R., Barrio, I., Cela, R., Quintana, J.B., 2017. Wastewaterbased epidemiology as a new tool for estimating population exposure to phthalate plasticizers. Environ. Sci. Technol. 51, 3902-3910.

Gracia-Lor, E., Castiglioni, S., Bade, R., Been, F., Castrignano, E., Covaci, A., GonzalezMarino, I., Hapeshi, E., Kasprzyk-Hordern, B., Kinyua, J., Lai, F.Y., Letzel, T., Lopardo, L., Meyer, M.R., O'Brien, J., Ramin, P., Rousis, N.I., Rydevik, A., Ryu, Y. Santos, M.M., Senta, I., Thomaidis, N.S., Veloutsou, S., Yang, Z., Zuccato, E., Bijlsma, L., 2017. Measuring biomarkers in wastewater as a new source of epidemiological information: current state and future perspectives. Environ. Int. 99, 131-150.

Heckmann, L.H., Sibly, R.M., Timmermans, M.J., Callaghan, A., 2008. Outlining eicosanoid biosynthesis in the crustacean Daphnia. Front. Zool. 5, 11.

Jahn, U., Galano, J.M., Durand, T., 2008. Beyond prostaglandins-chemistry and biology of cyclic oxygenated metabolites formed by free-radical pathways from polyunsaturated fatty acids. Angew Chem. Int. Ed. Engl. 47, 5894-5955.

Kalyanaraman, B., 2013. Teaching the basics of redox biology to medical and graduate students: oxidants, antioxidants and disease mechanisms. Redox Biol 1, 244-257.

Lang, M.R., Gihr, G., Gawaz, M.P., Muller II, 2010. Hemostasis in Danio rerio: is the zebrafish a useful model for platelet research? J. Thromb. Haemostasis 8 , 1159-1169.

Liu, T., Stern, A., Roberts, L.J., Morrow, J.D., 1999. The isoprostanes: novel prostaglandin-like products of the free radical-catalyzed peroxidation of arachidonic acid. J. Biomed. Sci. 6, 226-235.

Lushchak, V.I., 2014. Free radicals, reactive oxygen species, oxidative stress and its classification. Chem. Biol. Interact. 224, 164-175.

Metcalfe, N.B., Alonso-Alvarez, C., 2010. Oxidative stress as a life-history constraint: the role of reactive oxygen species in shaping phenotypes from conception to death. Funct. Ecol. 24, 984-996.

Milne, G.L., 2017. Classifying oxidative stress by F2-Isoprostane levels in human disease: the re-imagining of a biomarker. Redox Biol 12, 897-898.

Milne, G.L., Dai, Q., Roberts 2nd, L.J., 2015. The isoprostanes-25 years later. Biochim. Biophys. Acta 1851, 433-445.

Milne, G.L., Yin, H., Hardy, K.D., Davies, S.S., Roberts 2nd, L.J., 2011. Isoprostane generation and function. Chem. Rev. 111, 5973-5996.

Mizutani, S., Tanaka, M., Wheelock, C.E., Kanehisa, M., Goto, S., 2010. Phylogenetic analysis of lipid mediator GPCRs. Genome Inform 24, 116-126.

Morrow, J.D., Hill, K.E., Burk, R.F., Nammour, T.M., Badr, K.F., Roberts 2nd, L.J., 1990. A series of prostaglandin F2-like compounds are produced in vivo in humans by a non-cyclooxygenase, free radical-catalyzed mechanism. Proc. Natl. Acad. Sci. U. S. A. 87, 9383-9387.

Pham-Huy, L.A., He, H., Pham-Huy, C., 2008. Free radicals, antioxidants in disease and health. Int. J. Biomed. Sci. 4, 89-96.

Pisoschi, A.M., Pop, A., 2015. The role of antioxidants in the chemistry of oxidative stress: a review. Eur. J. Med. Chem. 97, 55-74.

Rahal, A., Kumar, A., Singh, V., Yadav, B., Tiwari, R., Chakraborty, S., Dhama, K., 2014. Oxidative stress, prooxidants, and antioxidants: the interplay. BioMed Res. Int. 2014, 761264.

Ricciotti, E., FitzGerald, G.A., 2011. Prostaglandins and inflammation. Arterioscler. Thromb. Vasc. Biol. 31, 986-1000.

Rico, M., Andres-Costa, M.J., Pico, Y., 2017. Estimating population size in wastewaterbased epidemiology. Valencia metropolitan area as a case study. J. Hazard Mater. 323, 156-165.

Rousis, N.I., Zuccato, E., Castiglioni, S., 2017. Wastewater-based epidemiology to assess human exposure to pyrethroid pesticides. Environ. Int. 99, 213-220.

Ryu, Y., Gracia-Lor, E., Bade, R., Baz-Lomba, J.A., Bramness, J.G., Castiglioni, S., Castrignano, E., Causanilles, A., Covaci, A., de Voogt, P., Hernandez, F., KasprzykHordern, B., Kinyua, J., McCall, A.K., Ort, C., Plosz, B.G., Ramin, P., Rousis, N.I., Reid, M.J., Thomas, K.V., 2016. Increased levels of the oxidative stress biomarker 8-iso-prostaglandin F2alpha in wastewater associated with tobacco use. Sci. Rep. 6, 39055.

Ryu, Y., Reid, M.J., Thomas, K.V., 2015. Liquid chromatography-high resolution mass spectrometry with immunoaffinity clean-up for the determination of the oxidative stress biomarker 8-iso-prostaglandin F2alpha in wastewater. J. Chromatogr. A 1409, 146-151.

Salin, K., Auer, S.K. Villasevil, E.M., Anderson, G.J., Cairns, A.G., Mullen, W. Hartley, R.C., Metcalfe, N.B., 2017. Using the MitoB method to assess levels of reactive oxygen species in ecological studies of oxidative stress. Sci. Rep. 7, 41228.

Santos, J.M., Jurban, M., Kim, H., 2015. Could sewage epidemiology be a strategy to assess lifestyle and wellness of a large scale population? Med. Hypotheses 85, 408-411.

Santos, J.M., Putt, D.A., Jurban, M., Joiakim, A., Friedrich, K., Kim, H., 2016. Differential BPA levels in sewage wastewater effluents from metro Detroit communities. Environ. Monit. Assess. 188, 585.

Spokas, E.G., Harshman, S., Cohen, G.M., Jiang, C., Levine, J.M., Rodriguez, A.R. Foglein, J., Spur, B.W., 2008. Release of the lipid peroxidation marker 8-epiprostaglandin F2 $\alpha$ from isolated gill pavement cells. Environ. Toxicol. Chem. 27, 1569-1575.

Thomas, K.V., Amador, A., Baz-Lomba, J.A., Reid, M., 2017. Use of mobile device data to better estimate dynamic population size for wastewater-based epidemiology. Environ. Sci. Technol. 51, 11363-11370.

van't Erve, T.J., Lih, F.B., Jelsema, C., Deterding, L.J., Eling, T.E., Mason, R.P., 
Kadiiska, M.B., 2016. Reinterpreting the best biomarker of oxidative stress: the 8-iso-prostaglandin F2alpha/prostaglandin F2alpha ratio shows complex origins of lipid peroxidation biomarkers in animal models. Free Radic. Biol. Med. $95,65-73$.

van 't Erve, T.J., Kadiiska, M.B., London, S.J., Mason, R.P., 2017. Classifying oxidative stress by F2-isoprostane levels across human diseases: a meta-analysis. Redox Biol 12, 582-599.
Yen, H.C., Wei, H.J., Lin, C.L., 2015. Unresolved issues in the analysis of F2 isoprostanes, F4-neuroprostanes, isofurans, neurofurans, and F2-dihomoisoprostanes in body fluids and tissue using gas chromatography/negative-ion chemical-ionization mass spectrometry. Free Radic. Res. 49, 861-880.

Zuccato, E., Chiabrando, C., Castiglioni, S., Calamari, D., Bagnati, R., Schiarea, S. Fanelli, R., 2005. Cocaine in surface waters: a new evidence-based tool to monitor community drug abuse. Environ. Health 4. 